\title{
A aquisição da leitura em leitores principiantes: erros típicos no português europeu ${ }^{1}$
}

\author{
Edlia Simões² \\ Margarida Alves Martins 3
}

\section{Resumo}

0 estudo das estratégias que as crianças usam na leitura de palavras e a análise dos erros que tipicamente ocorrem ao longo do processo de aprendizagem numa dada ortografia são da maior importância para a compreensão do processo de aprendizagem da leitura. 0 objectivo deste trabalho foi perceber como se processa a aquisição da leitura no início do ensino fundamental no português europeu. Procurou-se saber se haveria diferenças na frequência de erros fonológicos e lexicais e no padrão de erros fonológicos entre os dois primeiros anos do ensino fundamental. Participaram 175 crianças do $1^{\circ}$ ano e 137 do $2^{\circ}$ ano de seis escolas. Foi aplicada uma prova de leitura oral de palavras. Os erros foram categorizados em fonológicos, com diversas subcategorias, e lexicais. Encontraram-se diferenças na frequência dos erros fonológicos e lexicais entre os dois anos, assim como nos subtipos de erros fonológicos que tipicamente ocorreram. Os erros de substituição foram os mais frequentes, tendo ocorrido mais nas consoantes e nos dígrafos. Seguiram-se os erros de adição e de supressão, que ocorreram sobretudo em sílabas complexas. Tais resultados, contribuindo para uma caracterização dos erros típicos nessa fase de aprendizagem, revelamse um instrumento importante na detecção de dificuldades precoces na aprendizagem da leitura e na adequação de estratégias de ensino-aprendizagem. Este estudo permite uma melhor compreensão dos processos usados pelas crianças na resolução dos problemas que as características da língua portuguesa lhes coloca, assim como poderá permitir uma intervenção educativa que conduza a um maior sucesso na aprendizagem da leitura.

\section{Palavras-chave}

Leitores principiantes - Aprendizagem - Leitura de palavras - Padrão de erros.

\footnotetext{
1- Financiado pelo programa UID/CED/04853/2013 da Fundação para a Ciência e a Tecnologia (FCT).

2- University of Saint Joseph, Macau, China. Contato: edlia.simoes@usj.edu.mo.

3 - ISPA - Instituto Universitário de Ciências Psicológicas, Sociais e da Vida, Lisboa, Portugal. Contato: mmartins@ispa.pt.
} 


\section{Reading acquisition in beginner readers: Typical errors in European Portuguese}

\section{Abstract}

The study of the strategies that children use in reading words and the analysis of errors that typically occur throughout the learning process are of critical importance for the understanding of reading acquisition. The objective of this study was to understand the process of reading acquisition in European Portuguese in the beginning of elementary school. We sought to know if there would be differences in the frequency of phonological and lexical errors and in the pattern of phonological errors between the first two years of elementary school. The participants were 175 children from the 1st year and 137 from the 2nd year from 6 schools. An oral word reading task was applied. The errors were categorized as phonological, with several subcategories, and lexical. Differences were found in the frequency of phonological and lexical errors between the two years as well as in the subtypes of phonological errors that typically occurred. The most frequent errors were in substitution, occurring mostly in the consonants and digraphs. Errors of addition and suppression mainly occurred in complex syllables. These results that contributed to a characterization of the typical errors in this learning phase are an important tool in the detection of early difficulties in the reading process and in the adequacy of teachinglearning strategies. This study allows for a better understanding of the processes used by children in solving the problems that the characteristics of the Portuguese language poses to them, as well as allowing for an educational intervention that leads to greater success in learning to read.

\section{Keywords}

Beginning learners - Learning - Word reading - Error pattern.

\section{Introdução}

Investigadores de vários campos, tais como a psicologia cognitiva, a psicologia da educação, a psicolinguística e a educação, têm vindo a contribuir para o estudo da leitura. Esse interesse reflete a importância teórica, assim como prática, da investigação dos processos da leitura. Com efeito, muitas crianças manifestam desde cedo dificuldades na aprendizagem da leitura que frequentemente persistem ao longo da escolaridade e afetam o sucesso escolar em diversas áreas para as quais o domínio da leitura é indispensável. Nesse contexto, o estudo dos processos envolvidos em tal aprendizagem é essencial para melhorar as estratégias de ensino e adaptá-las à diversidade dos alunos que frequentam os anos iniciais do ensino fundamental. 
Por forma a melhorar o ensino da leitura, importa perceber como se processa o desenvolvimento normal da sua aquisição. 0 estudo das estratégias que as crianças usam na leitura de palavras e a análise dos erros que tipicamente ocorrem ao longo do processo de aprendizagem numa dada ortografia são, assim, da maior importância.

É hoje consensual que a capacidade de reconhecimento de palavras escritas é uma das competências indispensáveis para um bom desempenho em leitura (COLTHEART, 2012), assim como uma competência que vai sendo adquirida pela criança à medida que se torna proficiente na leitura (EHRI, 2005). Nesse contexto, surgem os modelos de reconhecimento de palavras, de forma a tentar caracterizar os processos mentais envolvidos no processo de leitura proficiente. 0 modelo de dupla-via (COLTHEART, 2012; COLTHEART et al., 2001) é um dos mais influentes nesse domínio. Tal modelo preconiza que existem duas vias de ligação entre a escrita e a fala: a via lexical e a via não lexical ou fonológica. A primeira implica um acesso direto à pronúncia duma palavra armazenada na memória lexical, espécie de dicionário interno em que as palavras conhecidas vão sendo guardadas. A via não lexical implica que o acesso à pronúncia de uma palavra passe pela transformação dos grafemas em fonemas, ou seja, pelas regras de correspondência grafema-fonema, e pela montagem da pronúncia da palavra a partir dessa sequência de fonemas.

Tendo por base esse modelo, a aquisição da leitura tem sido estudada através da leitura oral de palavras. Com efeito, a análise do tipo de erros que as crianças cometem na leitura oral de palavras pode indicar a estratégia subjacente ao desempenho na leitura, como também permitir perceber a mudança de processos cognitivos ao longo do desenvolvimento (MCGEOWN et al., 2013). Os erros de leitura são geralmente divididos em duas grandes categorias - erros lexicais e erros fonológicos.

Os erros lexicais são aqueles em que ocorre a substituição da palavra-alvo por uma palavra real visualmente ou foneticamente similar. Na literatura, esse tipo de erro tem sido denominado erro visualmente similar, paralexia verbal, erro ortográfico ou respostas palavras reais. Os erros lexicais refletem a utilização da via lexical ou direta de acesso ao léxico mental.

Os erros fonológicos, designação mais unânime na literatura, são aqueles em que existe uma alteração em alguma correspondência grafema-fonema da palavra, resultando a leitura numa não-palavra. Esses erros, que refletem uma dificuldade em usar a via indireta para aceder ao léxico mental, podem ser de substituição, supressão, adição, inversão, acentuação, tonicidade e regularização, entre outros. Os erros fonológicos refletem uma dificuldade em usar a via indireta para aceder ao léxico mental. É natural que uma maior complexidade nas correspondências grafema-fonema possa levar a mais erros desse tipo durante o processo de aquisição da leitura.

Vários estudos comparativos entre ortografias com correspondências fonema-grafema mais ou menos diretas, ou seja, com diversos graus de transparência, conseguiram perceber que, embora se utilizem estratégias fonológicas e lexicais, em todas elas existe uma prevalência das estratégias fonológicas na leitura de palavras nas fases iniciais de aquisição da leitura (SEYMOUR et al., 2003; SERRANO et al., 2010).

Seymour et al. (2003) realizaram um estudo translinguístico em que analisaram a aquisição da leitura em 13 línguas europeias, através da avaliação da identificação 
de letras, da leitura de palavras familiares e não-palavras em crianças do $1^{\circ}$ e do $2^{\circ}$ ano de escolaridade. Essas ortografias variavam quanto à sua transparência: desde as mais transparentes, como o espanhol; às intermédias, como o português e o francês; e às menos transparentes ou opacas, como o inglês. Também variavam ao nível da complexidade silábica: desde o espanhol ou o português, com estruturas silábicas simples; ao francês e ao inglês, com estruturas silábicas complexas. Os leitores do português, do francês, do dinamarquês e do inglês foram identificados como aqueles que apresentaram menores acuidade e fluência na leitura de palavras familiares, tendo os leitores portugueses obtido resultados inferiores. Na leitura de não-palavras, os leitores do português e do francês foram os que apresentaram maior dificuldade na decodificação, tendo mais uma vez os leitores do português obtido resultados inferiores, apesar de o português ter uma estrutura silábica simples. Os autores argumentam que existe um limiar de complexidade ortográfica a partir do qual, em vez de se utilizar apenas um processo-base para a leitura (ortografias transparentes), passaria a ser necessário usar dois processos-base com mecanismos distintos de decodificação e reconhecimento de palavras. Foi descrito que o português se encontra acima desse limiar, ou seja, a aquisição da leitura se processa mais como nas ortografias mais opacas.

Por sua vez, Serrano et al. (2010) realizaram um estudo longitudinal em que compararam a aquisição da leitura e da escrita de palavras em português, francês e espanhol. As tarefas eram muito similares às utilizadas no estudo de Seymour et al. (2003). Em relação à leitura de palavras e de pseudopalavras, as crianças espanholas tiveram resultados superiores aos das crianças portuguesas e francesas. Os autores explicam esses resultados com base em uma maior inconsistência na correspondência grafema-fonema nas línguas portuguesa e francesa.

Num estudo comparativo entre o português europeu e o espanhol nos primeiros anos de aquisição da leitura, Defior et al. (2002) verificaram que o número de erros fonológicos tendia a diminuir ao longo da escolaridade e que o número de erros lexicais tendia a aumentar. As crianças portuguesas, mesmo no $4^{\circ}$ ano de escolaridade, cometeram mais erros fonológicos do que as espanholas, não tendo havido diferenças entre as duas ortografias nos erros lexicais, excepto no $1^{\circ}$ ano. Curiosamente, no $1^{\circ}$ ano, as crianças portuguesas fazem um maior número de erros lexicais, o que parece indicar que recorrem mais precocemente aos processos da via direta ou lexical na leitura. Devido à similaridade no padrão dos resultados, os autores afirmam que as crianças das duas ortografias utilizam as mesmas estratégias de leitura, apesar de as crianças portuguesas terem mais dificuldades devido à maior complexidade das correspondências fonema-grafema. As características do português europeu, que é considerado uma ortografia intermédia ou semitransparente, em que as correspondências grafema-fonema não são de um-para-um, em que existem regras contextuais e irregularidades, podem explicar os resultados obtidos quando comparados com os das crianças espanholas.

Diversos estudos têm sido realizados no sentido de perceber como evoluem os erros de leitura ao longo da escolaridade em crianças brasileiras. Esses estudos têm demonstrado que existe um predomínio da utilização de estratégias fonológicas na fase inicial de aprendizagem da leitura, vindo a ser substituídas pelo recurso a estratégias lexicais ou 
ortográficas em fases mais avançadas na aquisição da leitura (CUNHA; CAPELLINI, 2010; PINHEIRO, 1994, 1995; PINHEIRO et al., 2008; SALLES; PARENTE, 2007).

Cunha e Capellini (2010) caracterizaram os erros de leitura em crianças do $1^{\circ}$ ao $4^{\circ}$ ano de escolaridade, aplicando provas de leitura de palavras e pseudopalavras. Classificaram os erros na leitura de palavras em cinco categorias: regularizações, palavras visualmente semelhantes, tentativas de som malsucedidas, falha na aplicação de regras ortográficas e recusas. Para as pseudopalavras, retiraram o erro de regularização e de palavra visualmente semelhante e substituíram este último por lexicalização (leitura de pseudopalavra por palavra real). As autoras verificaram diferenças significativas para todos os erros por ano de escolaridade, exceto para o erro recusas. 0 padrão da tipologia de erros foi o mesmo em todos os anos de escolaridade, quer para a leitura de palavras, quer de pseudopalavras, sendo as tentativas de som malsucedidas o erro mais frequente. As autoras concluem que o uso da via fonológica para a decodificação é importante para palavras novas e desconhecidas e que a passagem para a leitura lexical depende das capacidades fonológicas e da eficaz aprendizagem das regras ortográficas, as quais formarão o léxico ortográfico.

Também Pinheiro (1994, 1995), na sua análise qualitativa dos erros de leitura em palavras reais, obteve majoritariamente erros fonológicos que resultavam em neologismos, isto é, não-palavras. Estas eram caracterizadas por omissões, repetição de letras e troca de letras nas consoantes e vogais. A autora encontrou muitos erros de regularização, que aconteciam muito frequentemente nas palavras irregulares com o grafema $<\mathrm{x}>$, assim como nas palavras com consoantes dependentes do contexto, como $0<$ s $>$ intervocálico. Esse tipo de erro envolvendo regras tendeu a diminuir com o avanço na escolaridade, embora tenha persistido nas crianças com dificuldades de leitura.

Salles e Parente (2007), num estudo sobre o tipo de erros no $2^{\circ}$ ano de escolaridade, verificaram que, na leitura de palavras reais, as crianças cometeram maior número de erros por regularização do que erros lexicais e de desconhecimento de regra dependente do contexto, evidenciando uma predominância do uso da via fonológica sobre a lexical na leitura.

Diversos estudos demonstraram que a complexidade nas correspondências fonema-grafema, assim como a estrutura silábica afetam a aquisição da leitura (BARCA et al., 2007; RAHBARI; SÉNÉCHAL, 2010; SPRENGER-CHAROLLES; SIEGEL, 1997).

Em termos de erros produzidos nas vogais e consoantes, Loff e Vale (2007) verificaram, no português europeu, que as crianças do $1^{\circ}$ ano apresentavam maior número de erros nas vogais do que nas consoantes, o que pode ser explicado pela complexidade das regras de correspondência fonema-grafema em que às cinco letras vogais correspondem 18 fonemas. No entanto, no espanhol (GOIKOETXEA, 2006), no italiano (COSSU et al., 1995) e no francês (SPRENGER-CHAROLLES; SIEGEL, 1997), os erros de substituição da consoante foram mais frequentes que os erros de substituição da vogal. Os erros de substituição da consoante mais frequentes foram nas consoantes dependentes do contexto (GOIKOETXEA, 2006; VALLE-ARROYO, 1989), tendendo as crianças a regularizar essas consoantes, lendo-as com o valor fonético mais comum.

Em várias ortografias as crianças apresentam, também, dificuldades no caso dos dígrafos. Existe evidência de que, mesmo recebendo instrução explícita sobre os dígrafos, 
elas tendem a desenvolver uma compreensão tardia da utilização destes (EHRI; SOFFER, 1999). Nunes e Aldinis (1999), no português do Brasil, verificaram que as crianças nos primeiros anos de escolaridade cometiam mais erros em palavras que continham dígrafos em oposição às que não continham e que os leitores mais fracos tinham maiores dificuldades com os dígrafos. Os autores avançam a hipótese de esses leitores não entenderem a necessidade do dígrafo consonantal para representar um som por dificuldades fonológicas (ex.: diferença entre $0<n>$ e $o<n h>$ ) ou, então, pela dificuldade do uso de grafemas que envolvem mais do que uma letra (NUNES; BYRANT, 2014). Mesmo na linguagem oral, os dígrafos apresentam uma determinada ordem de aquisição, sendo que o dígrafo <nh>, consonante nasal [n], é o primeiro a ser adquirido, seguido do $<\mathrm{ch}>$, consoante fricativa [J], e do <lh>, consoante lateral [ $K$ ] (FREITAS et al., 2012).

No português, também existem regras de posição, isto é, as consoantes duplas apenas poderão surgir no meio de duas vogais e nunca no início ou no final das palavras. Rego e Buarque (1999), no português do Brasil, verificaram que as crianças, nos primeiros anos de escolaridade, optam por substituir o dígrafo $<$ rr $>$ por $<$ r $>$, talvez por estarem a basear a sua escrita no princípio alfabético de que cada som corresponde a uma letra.

Em relação à estrutura silábica, Sprenger-Charolles e Siegel (1997) estudaram os efeitos da estrutura silábica no desenvolvimento da leitura e da escrita, no francês, em crianças do $1^{\circ}$ ano de escolaridade. Verificaram que houve melhor desempenho em pseudopalavras com estrutura silábica simples CV quando comparado com estruturas silábicas complexas como CCV e CVC. Goikoetxea (2006), no espanhol, e Monteiro (2007) e Monteiro e Soares (2014), no português do Brasil, também verificaram que as crianças apresentavam muitas dificuldades na leitura de sílabas complexas e utilizavam estratégias de leitura de modo a transformar as sílabas mais complexas em sílabas canónicas.

No estudo de Monteiro (2007), com crianças com dificuldades de leitura, as estratégias mais utilizadas para a resolução da dificuldade de leitura de sílabas complexas foram: a omissão da ramificação do ataque em sílabas do tipo CCV; a omissão da coda em sílabas do tipo CVC; e a inserção de grafemas na leitura de sílabas do tipo CVC. Segundo Monteiro e Soares (2014), a conjugação de uma consoante com uma vogal seria o modelo de decodificação-base, ao qual as crianças voltariam quando enfrentam dificuldades com as sílabas complexas. No entanto, essa estratégia torna-se ineficiente para decodificar palavras com sílabas complexas ou mesmo com correspondências grafema-fonema sujeitas a regras de contexto. Desta forma, a dificuldade de aquisição das regras de correspondência grafema-fonema, assim como dos padrões ortográficos da língua levam as crianças a cometer erros de leitura. 0 desenvolvimento de tais competências torna-se fundamental para a aprendizagem da leitura e para o uso eficaz da via lexical.

Poucos são os estudos efetuados no português europeu, relativos à forma como os erros em leitura evoluem nos primeiros anos do ensino fundamental. Mencionaremos os de Gomes (2001), Loff e Vale (2007) e de Fernandes et al. (2008).

Gomes (2001) verificou, através da análise de erros de leitura de crianças do $1^{\circ}$ ao $3^{\circ}$ ano de escolaridade, que a maioria dos erros ocorreu em palavras com sílabas complexas. 0 maior número de erros de leitura verificou-se no $1^{\circ}$ ano de escolaridade, sendo que no $2^{\circ}$ e no $3^{\circ}$ ano os erros já se encontravam em reduzido número. Tendo por base a 
análise da estrutura silábica cruzada com o tipo de erros, os resultados indicaram que, na estrutura VCVC e CCVCV, as crianças do $1^{\circ}$ ano utilizam maioritariamente a adição, enquanto na estrutura CVCCV predomina a omissão. $\mathrm{Na}$ estrutura $\mathrm{CV} C \mathrm{CV}$, as crianças também demonstraram tendência a adicionar uma vogal ou a omitir a nasalização.

Loff e Vale (2007) analisaram os tipos de erros que crianças dos quatro primeiros anos do ensino fundamental cometeram na leitura de uma lista de palavras. Os resultados mostram que a percentagem média de erros diminuía drasticamente do $1^{\circ}$ para $02^{\circ}$ ano, não se verificando diferenças estatisticamente significativas do $3^{\circ}$ para o $4^{\circ}$ ano. No que diz respeito às categorias de erros, observaram que os erros que implicavam falhas na análise fonémica da palavra eram cometidos mais frequentemente do que os erros por regularização. Apenas no $4^{\circ}$ ano esse padrão é invertido. No entanto, o estudo não revelou diferenças significativas entre os anos de escolaridade para as diferentes categorias de erro. Em conclusão, as autoras afırmam que a progressão quantitativa faz-se de forma nítida ao longo dos quatro anos, mas as estratégias de leitura, com excepção da mudança entre o $1^{\circ}$ e o $2^{\circ}$ ano, tendem a ser muito semelhantes, tanto nos leitores mais iniciantes como nos mais avançados. As crianças parecem construir um léxico ortográfico logo a partir do $1^{\circ}$ ano de escolaridade, mas a estratégia de leitura continua a ser maioritariamente a decodificação fonológica até ao final do $4^{\circ}$ ano.

Fernandes et al. (2008), num estudo com crianças portuguesas do $1^{\circ}$ ano de escolaridade, através da avaliação da leitura e da escrita de palavras e pseudopalavras, verificaram um efeito de regularidade e de complexidade grafêmica, indicando que as crianças dependem do processo de conversão grafema-fonema para a leitura de palavras nessa fase inicial de aprendizagem da leitura.

Dada a importância desse tipo de estudo para a compreensão do processo de aprendizagem da leitura e dado o fato de a investigação no português europeu ser ainda reduzida, tivemos como objectivos perceber quais são os tipos de erros mais frequentes nos dois primeiros anos de escolaridade e compreender, através de uma análise qualitativa, em que correspondências fonema-grafema os erros eram mais frequentemente cometidos, tentando perceber quais são as correspondências mais problemáticas para as crianças. Procuramos, assim, responder às seguintes questões de investigação:

Haverá diferenças na frequência de erros fonológicos e lexicais entre o $1^{\circ}$ e o $2^{\circ}$ ano de escolaridade?

Haverá diferença no padrão de erros fonológicos entre o $1^{\circ}$ e o $2^{\circ}$ ano de escolaridade?

\section{Método}

\section{Participantes}

Participaram neste estudo 175 crianças do $1^{\circ}$ ano de escolaridade e 137 crianças do $2^{\circ}$ ano de escolaridade de seis escolas do $1^{\circ}$ ciclo do ensino fundamental (quatro escolas públicas, sendo cinco turmas do $1^{\circ}$ ano e cinco do $2^{\circ}$ ano; e duas escolas privadas, sendo quatro turmas do $1^{\circ}$ ano e duas turmas do $2^{\circ}$ ano) do Distrito de Lisboa, Portugal. Do $1^{\circ}$ ano, havia 75 participantes do sexo feminino e 100 do sexo masculino; do $2^{\circ}$ ano, havia 
63 do sexo feminino e 74 do sexo masculino. A média de idades das crianças do $1^{\circ}$ ano era de 84.01 meses $(D P=4.06)$ e do $2^{\circ}$ ano era de 95.63 meses $(D P=4.51)$.

Com relação ao nível de escolaridade dos pais, verifıcamos que a maioria possui o equivalente ao ensino médio (pais: 27\%; mães: 25.3\%) ou frequentou o ensino superior (pais: 32.1\%; mães: 36\%). As escolas públicas encontravam-se em meios socioeconómicos médios/médio-baixos, enquanto as escolas privadas estavam localizadas em meios socioeconómicos médio-alto/altos.

Solicitou-se autorização de participação às escolas, assim como aos pais de todas as crianças.

Foi realizado um questionário aos professores em relação ao seu método de ensino da leitura. A maioria dos professores afırmou utilizar um método analítico-sintético.

Foram selecionadas apenas crianças que tivessem iniciado a aquisição da linguagem escrita no português como primeira língua e que não tivessem necessidades educativas especiais.

\section{Tarefas}

Foi aplicada uma Prova de Leitura Oral de Palavras (ALVES MARTINS; SIMÕES, 2008) para o $1^{\circ}$ e para o $2^{\circ}$ ano de escolaridade. Esta é constituída por uma lista de 32 palavras que variam quanto à regularidade, à frequência, à extensão e à estrutura silábica. Das 32 palavras, 16 são regulares e 16 são irregulares; 21 são pouco frequentes e 11 são frequentes. 0 número de letras das diferentes palavras varia entre 4 e 9, havendo 19 palavras curtas e 13 longas. No que respeita à estrutura silábica, consideraram-se palavras com diferentes formatos silábicos.

Relativamente à consistência interna da prova, o valor do coeficiente $\alpha$ de Cronbach foi de 0.97. Pode-se considerar, assim, que a prova apresenta elevada consistência interna.

A prova é de administração individual e foi apresentada em suporte de papel.

Foram dadas as seguintes instruções:

"Lê, em voz alta, as palavras que se seguem nesta lista, o melhor que tu fores capaz e o mais rapidamente que conseguires."

Cada resposta correta foi cotada com 1 ponto, podendo os resultados variar de 0 a 32 pontos. Foi cronometrado o tempo de realização da prova, o que permitiu calcular, para cada criança, o número de palavras corretamente lidas por minuto.

\section{Procedimento}

A prova foi realizada numa sala próxima da sala de aula, estando esta livre de distrações e com reduzido barulho nas imediações. A prova foi realizada individualmente com a criança e o investigador. A leitura foi gravada em formato de áudio, com o programa Audacity, e transcrita a forma escrita da palavra lida oralmente. 
De forma a poder analisar os resultados, procedemos à cotação dos erros de leitura cometidos. Para tal, construímos uma grade de classificação dos tipos de erro adaptada a partir de estudos realizados no português do Brasil (ÁVILA et al., 2009; PINHEIRO et al., 2008; SALLES, 2005; SALLES; PARENTE, 2007) e por autores de outras línguas (DEFIOR et al., 2002; GOIKOETXEA, 2006; GOULANDRIS, 2004).

A codificação dos erros foi realizada separadamente por dois investigadores, tendo-se obtido níveis elevados de concordância (kapa=0.91).

Apresentamos a classificação dos tipos de erros que serviram de base para a análise das respostas incorretas.

Consideramos duas grandes categorias de erros: fonológicos e lexicais.

- Erros fonológicos: ocorrem quando existe substituição, adição, supressão, inversão ou mudança de acentuação.

- Erros por substituição: substituição de um fonema(as) por outro, podendo tratar-se de vogais (ex.: <oval> lido como uval), consoantes (ex.: < fritar> lido como britar) ou dígrafos vocálicos ou consonantais (ex.: <unhas> lido como ulhas).

- Erros por adição: adição de um ou mais fonemas numa palavra (ex.: <blusa> lido como belusa; <fritar> lido como fritare; <clarão> lido como calarão).

- Erros por supressão: supressão de um ou mais fonemas sequenciais ou sílabas, ou supressão de uma vogal de um ditongo (ex.: <clarão> lido como carão; <próximo> lido como póximo).

- Erros por inversão: inversão de dois ou mais grafemas que constituem a palavra, ou troca na ordem das sílabas na palavra (ex.: <clarão> lido como calrão; <lavrador> lido como lavardor).

- Erros de acentuação: alteração da tonicidade da palavra, isto é, tanto a leitura incorreta da acentuação como a alteração da acentuação na palavra (ex.: <arroz> lido como árroz; <hortelã> lido como hortéla).

Todos esses erros podem ocorrer mais do que uma vez por palavra. Cada resposta incorreta foi sujeita a cotação de erros até a um máximo de quatro erros por palavra.

- Erros lexicais: ocorrem quando uma palavra-alvo é lida como outra palavra real, sendo essa leitura provocada por proximidade ortográfica ou fonológica com a palavra-estímulo (ex.: < vozes> lido como vocês; <blusa> lido como bolsa). Esse tipo de erro ocorre apenas uma vez por palavra.

\section{Resultados}

Apresentam-se, na Tabela 1, as médias e os desvios-padrão dos erros fonológicos e lexicais para os dois primeiros anos de escolaridade. Apesar de os erros fonológicos poderem ocorrer mais do que uma vez por palavra, nesta análise só foram contabilizados uma vez por palavra, para permitir comparações com os erros lexicais. 
Tabela 1- Médias e desvios-padrão dos erros fonológicos e lexicais no $1^{\circ}$ e no $2^{\circ}$ ano de escolaridade.

\begin{tabular}{cccccc}
\hline & \multicolumn{2}{c}{$1^{\circ}$ ano } & & \multicolumn{2}{c}{$2^{\circ}$ ano } \\
\cline { 2 - 5 } Tipos de erro & $M$ & $D P$ & & $M$ & $D P$ \\
\hline Fonológicos & 8.68 & 7.67 & & 4.03 & 4.31 \\
Lexicais & & & & \\
\hline
\end{tabular}

Fonte: Dados da pesquisa

Como podemos observar na Tabela 1, a média de erros fonológicos é superior à média de erros lexicais tanto no $1^{\circ}$ como no $2^{\circ}$ ano. No entanto, a frequência de erros fonológicos diminui do $1^{\circ}$ para o $2^{\circ}$ ano, enquanto a frequência de erros lexicais aumenta do $1^{\circ}$ para o $2^{\circ}$ ano. Os erros fonológicos ocorreram em 87\% (160/175 crianças) da amostra do $1^{\circ}$ ano. No $2^{\circ}$ ano, os erros fonológicos ocorreram em $85.1 \%$ (120/137 crianças) da amostra. Os erros lexicais ocorreram em 18.3\% (32/175 crianças) da amostra dos alunos do $1^{\circ}$ ano. No $2^{\circ}$ ano, os erros lexicais ocorreram em 34.3\% (47/137 crianças) da amostra. Os erros lexicais encontrados com maior frequência no $2^{\circ}$ ano foram nas seguintes palavras: <quadros> lido como quadrados; <blusa > lido como bolsa; <raiz> lido como reis; e <vozes> lido como vocês.

De modo a efetuar a comparação entre o $1^{\circ}$ e $02^{\circ}$ ano de escolaridade, foram realizados dois testes t para amostras independentes, tendo como variável independente o ano de escolaridade e como variáveis dependentes os erros lexicais e os erros fonológicos. Os resultados mostram que existem diferenças estatisticamente significativas nos erros fonológicos entre o $1^{\circ}$ e o $2^{\circ}$ ano de escolaridade (t $\left.(283,63)=6.77 ; p<.001\right)$, sendo que no $1^{\circ}$ ano existe um maior número de erros fonológicos em comparação com o $2^{\circ}$ ano. Quanto ao erros lexicais, também pudemos verificar diferenças estatisticamente significativas entre o $1^{\circ}$ e o $2^{\circ}$ ano de escolaridade $(t(200,55)=-3,68 ; p<.001)$, de modo que no $2^{\circ}$ ano as crianças obtêm uma média de erros lexicais superior em relação aos alunos do $1^{\circ}$ ano.

\section{Subcategorias dos erros fonológicos}

Apresentam-se, na Tabela 2, as médias e os desvios-padrão relativamente às subcategorias dos erros fonológicos das crianças do $1^{\circ}$ e do $2^{\circ}$ ano. Tal como foi referido anteriormente, esses erros podem ocorrer mais do que uma vez por palavra. Nesta análise, tivemos em conta a totalidade de erros fonológicos cometidos pelas crianças. 
Tabela 2- Médias e desvios-padrão das subcategorias dos erros fonológicos no $1^{\circ}$ e no $2^{\circ}$ ano de escolaridade.

\begin{tabular}{ccccc}
\hline & \multicolumn{2}{c}{$1^{\circ}$ ano } & \multicolumn{2}{c}{$2^{\circ}$ ano } \\
\cline { 2 - 5 } Tipos de erro & $M$ & $D P$ & 2.82 & 3.93 \\
\hline Substituição & 6.99 & 7.46 & 0.5 & 1.02 \\
Adição & 2.51 & 4.25 & 0.74 & 1.41 \\
Supressão & 2.11 & 3.02 & 1.26 & 1.33 \\
Acentuação & 1.9 & 1.77 & & 0.97 \\
Inversão & 0.64 & 1.11 & 0.38 & 0.97 \\
\hline
\end{tabular}

Fonte: Dados da pesquisa.

Podemos verificar que o erro de substituição, tanto no $1^{\circ}$ ano como no $2^{\circ}$ ano, é o mais frequente (ex.: <mentiu> lido como mendiu; ou <arroz> lido como arruz). Em segundo lugar, verificam-se os erros de adição (ex.: < fritar> lido como feritar), seguidos dos erros de supressão (ex.: <cristal> lido como crital) e dos erros de acentuação (ex.: $<$ hortelã > lido como hortéla). No $2^{\circ}$ ano, a ordem desses três tipos de erros altera-se, passando os erros de acentuação a ser os mais frequentes, seguidos de erros de supressão e por fim de adição. 0 erro menos frequente é o de inversão nos dois anos (ex.: <clarão> lido como calrão). A hierarquia dos subtipos de erros fonológicos não é a mesma, o que revela que o padrão de erros é diferente entre os dois anos de escolaridade.

Com a finalidade de comparar as várias subcategorias de erros fonológicos entre o $1^{\circ}$ e o $2^{\circ}$ ano de escolaridade, utilizamos o teste não-paramétrico de Mann-Whitney. Verificamos que existem diferenças significativas entre todas as subcategorias de erros: erros de substituição ( $U=7908,00 ; p<.001)$; erros de adição ( $U=8263,50 ; p<.001)$; erros de supressão (U=8475,50; $p<.001)$; erros de acentuação $(U=9349,00 ; p<.001)$ e erros de inversão ( $\mathrm{U}=10170,50 ; p<.01)$.

Visto os erros de substituição serem os mais frequentes, iremos analisar mais adiante os subtipos de erros de substituição com maior detalhe.

No que respeita aos erros de adição, estes ocorreram com maior frequência nas palavras iniciadas pela sílaba CCV, sendo que as crianças adicionavam maioritariamente uma vogal à sílaba CCV, sendo esta geralmente o fonema [e] (ex.: <blusa> lido como belusa; <trincha> como terincha; ou <glutões> como guelutões). 
No que diz respeito aos erros de supressão, as crianças também utilizam essa estratégia para resolver a leitura das sílabas CCV (ex.: <plantei> lido como pantei; ou $<$ próximo > lido como póximo) para a leitura do plural (ex.: < vozes> lido como voz; $<$ jovens $>$ lido como jovem) e em palavras como <zarolho $>$, lida como zaro para resolver a leitura do dígrafo.

Em relação aos erros de acentuação, estes são frequentes nos dois anos de escolaridade, nas seguintes palavras: raiz, vozes, águias, hortelã e exerço. Nas palavras <águias> e <hortelã>, as crianças retiram a acentuação, resultando na leitura de aguias e hortéla. Nas palavras <vozes > ou <exerço > as crianças alteram a tonicidade de vogais, resultando na leitura de vozés e exerço, sendo o [e] substituído por [ $[\varepsilon$ ] devido a este valor fonético ser o mais comum e também por ser o nome da letra. Por último, na palavra $<$ raiz $>$, as crianças leram rais, ignoraram o hiato.

Finalmente, os erros menos frequentes, os de inversão, ocorrem maioritariamente no $1^{\circ}$ ano de escolaridade. Esse tipo de erro ocorre principalmente nas palavras que contêm a sílaba CCV (ex.: < próximo> lido como pórximo; <blusa > lido como <bulsa >; ou <clarão> como calrão).

\section{Subtipos dos erros de substituição}

Os erros de substituição subdividem-se em quatro subtipos: erro de substituição da consoante; erro de substituição da vogal; erro de dígrafo vocálico e erro de dígrafo consonantal.

Apresentamos na Tabela 3 a sua distribuição pelo $1^{\circ}$ e pelo $2^{\circ}$ ano segundo o índice percentual de erro. Este foi calculado através do número de erros a dividir pelo número de possibilidade de ocorrência do tipo de erro em causa. Os resultados foram transformados em percentagens.

Tabela 3- Índice percentual de erros dos subtipos de erros de substituição.

\begin{tabular}{|c|c|c|c|c|}
\hline \multirow[b]{2}{*}{ Subtipos de erro de substituição } & \multicolumn{2}{|c|}{$1^{\circ}$ ano } & \multicolumn{2}{|c|}{$2^{\circ}$ ano } \\
\hline & M & $D P$ & M & $D P$ \\
\hline Consoante & 15.81 & 23.45 & 5.72 & 13.17 \\
\hline Vogal & 7.1 & 12.43 & 2.71 & 7.25 \\
\hline Dígrafo vocálico & 3.78 & 4.14 & 1.47 & 2.01 \\
\hline Dígrafo consonantal & 2.42 & 3.06 & 1.1 & 1.66 \\
\hline
\end{tabular}

\footnotetext{
Fonte: Dados da pesquisa.
} 
Verificamos que o subtipo de substituição da consoante é o erro mais frequente no $1^{\circ}$ ano, assim como no $2^{\circ}$ ano de escolaridade. As palavras em que as crianças cometem com maior frequência o erro de substituição da consoante são, por exemplo: <vozes> lido como vosses; <zarolho> lido como sarolho; ou <cristal> lido como sristal.

Existem, ainda, erros na consoante associados a regras explícitas que são desrespeitadas, tanto no $1^{\circ}$ ano quanto no $2^{\circ}$ ano, por exemplo: $0<\mathrm{s}>$ entre vogais que adquire o fonema [z], como em <casa $>$; ou o grafema $<$ g $>$ que, seguido de $<$ e $>$ ou $<\mathrm{i}>$, adquire o fonema [3] em vez de [g]. Exemplos frequentes desse tipo de erro são: <girassol> lido como guirassol; e <blusa> lido como blussa. Nessas palavras, as crianças substituem a consoante pelo seu valor fonético mais comum. Também na leitura de palavras irregulares ocorre esse mecanismo, como <táxi $>$, <próximo $>$ ou $<$ exerço $>$, em que a consoante $<\mathrm{x}>$ é lida como [J] (ex.: <táxi> lido como táchi).

Em seguida, aparece o erro de substituição da vogal. Nesse subtipo de erro, as crianças tendem a substituir a leitura do fonema [o] por [u] ou vice-versa, sendo as palavras com maior número de erros, por exemplo: <oval> lido como uval; <jovens> lido como juvens; e <glutões> lido como glotões.

Dentro das substituições de dígrafos, verificamos que o subtipo de erro nos dígrafos vocálicos é o mais frequente nos dois anos de escolaridade. No entanto, existe uma mudança na estratégia de leitura do dígrafo vocálico do $1^{\circ}$ para o $2^{\circ}$ ano de escolaridade. No $1^{\circ}$ ano, as crianças substituem a sílaba nasalizada por uma não nasalizada e adicionam uma vogal na sequência (ex.: <jovens> lido como jovenes; < plantei> lido como planetei). Já no $2^{\circ}$ ano, o erro no dígrafo vocálico é maioritariamente por supressão da nasal, substituindo a sílaba CV por V (ex.: <trincha> lido como tricha =; ou <serpentes > lido como serpetes).

Em segundo lugar aparece o subtipo de erro nos dígrafos consonantais, tanto no $1^{\circ}$ ano como no $2^{\circ}$ ano. As crianças tendiam a substituir um dígrafo consonantal por outro, por exemplo: <unhas> lido como ulhas; <trincha> lido como trinha; e <zarolho> lido como zaronho. No entanto, pudemos verificar uma maior substituição dos dígrafos [ch] e [lh] pelo dígrafo [nh].

Tanto no $1^{\circ}$ ano como no $2^{\circ}$ ano, as crianças substituem o dígrafo <gui>, na palavra <águias>, por <gu>, resultando na leitura de águ-ias. Especialmente no $1^{\circ}$ ano de escolaridade, as crianças substituem a leitura do <gui $>$ pela leitura [3i], resultando na leitura de <águias> como ágias.

Em relação ao dígrafo $<\mathrm{rr}>$, apenas as crianças do $1^{\circ}$ ano cometem erros, substituindo a leitura do dígrafo <rr> por [r], lendo, por exemplo, <arroz> como aroz. No $2^{\circ}$ ano, a leitura desse dígrafo está adquirida pelas crianças.

Em relação dígrafo <ss> na palavra <girassol>, apenas as crianças do $1^{\circ}$ ano substituíram maioritariamente o dígrafo $<$ ss $>$ por [z], aplicando de forma errónea a regra ortográfica de que o grafema $<\mathrm{s}>$ no meio de duas vogais corresponde ao fonema [z]. No $2^{\circ}$ ano, a leitura desse dígrafo está adquirida pelas crianças.

De modo a comparar o $1^{\circ} \mathrm{com}$ o $2^{\circ}$ ano de escolaridade em relação aos vários subtipos de erros de substituição, utilizamos o teste não-paramétrico de Mann-Whitney. Verificamos que existem diferenças significativas entre todos os subtipos de erros: erro 
de substituição da consoante $(U=8943,50 ; p<.001)$; erro de substituição da vogal $(U=$ 7853,50; $p<.001)$; erro de substituição do dígrafo vocálico $(U=9767,00 ; p<.001)$ e erro de substituição do dígrafo consonantal ( $U=9143,00 ; p<.001)$.

\section{Discussão}

A primeira questão a que procuramos responder foi a de saber se haveria diferenças na frequência de erros fonológicos e lexicais entre o $1^{\circ}$ e o $2^{\circ}$ ano de escolaridade, procurando contribuir para a compreensão do papel da via lexical e da via fonológica no reconhecimento de palavras nessa etapa de aprendizagem da leitura.

Os resultados mostraram que, do $1^{\circ}$ para o $2^{\circ}$ ano, os erros fonológicos diminuem e os lexicais aumentam. Mostram igualmente que a frequência dos erros fonológicos é superior à dos erros lexicais. Esses resultados vão no mesmo sentido dos obtidos por diversos autores (ÁVILA et al., 2009; CUNHA; CAPELLINI, 2010; LOFF; VALE, 2007; LÚCIO; PINHEIRO, 2011; MCGEOWN et al., 2013; PINHEIRO, 1994, 1995; PINHEIRO et al., 2008; SALLES; PARENTE, 2007). No entanto, no que diz respeito ao aumento dos erros lexicais do $1^{\circ}$ para o $2^{\circ}$, os nossos resultados divergem dos de Defior et al. (2002), em que os erros lexicais diminuíam do $1^{\circ}$ para o $2^{\circ}$ ano.

Pensamos que os erros lexicais ocorrem devido ao fato de as representações lexicais estarem ainda em construção, não estando totalmente definidas na memória lexical, o que pode levar a que as palavras sejam confundidas com outras visualmente próximas. Esses erros parecem refletir o uso da via direta de acesso ao léxico mental. Pelo contrário, os erros fonológicos que ocorrem devido a um domínio insuficiente das estratégias de decodificação refletem o uso da via indirecta na leitura.

Verificamos que as crianças do nosso estudo usam paralelamente, nos dois primeiros anos, esses dois tipos de estratégias para ler, o que vai no sentido do proposto pelo modelo de dupla via (COLTHEART, 2005; COLTHEART et al., 2001) e no sentido das conclusões de Fernandes et al. (2008, p. 819) quando afirmam:

Poder-se-ia pensar nestes dois processos, mediação fonológica e recurso ao léxico ortográfico, como competitivos. Nesta fase de aprendizagem da leitura e da escrita a sua relação parece ser antes de cooperação. A forte dependência na mediação fonológica cria provavelmente as condições para a consolidação da representação ortográfica das palavras.

No que diz respeito à nossa segunda questão de investigação em que procurávamos saber se haveria diferenças no padrão de erros fonológicos entre $01^{\circ}$ e $02^{\circ}$ ano de escolaridade, verificamos que o padrão dos diversos tipos de erros nos dois primeiros anos não é o mesmo. Se o erro de substituição é o mais frequente nos dois anos e o de inversão o menos frequente, já no $1^{\circ}$ ano o segundo erro mais frequente é o de adição, enquanto no $2^{\circ}$ ano é o de acentuação. 0 erro de supressão surge em $3^{\circ}$ lugar nos dois anos de escolaridade. Esses resultados vão em sentido diverso dos de Cunha e Capellini (2010), que observaram o mesmo padrão de organização de frequência de erros em todos os anos de escolaridade. 
A maior frequência de erros de substituição é, igualmente, observada em outros estudos (ÁVILA et al. 2009; GOIKOETXEA, 2006; GOMES, 2001; JIMÉNEZ; HERNANDEZ, 2000; PINHEIRO, 1994). É de salientar que o subtipo de erro de substituição na consoante foi mais frequente do que na vogal, tal como no italiano e no espanhol (COSSU et al., 1995; Goikoetxea, 2006), ao contrário dos resultados obtidos por Loff e Vale (2007) no português europeu.

Especificamente no que diz respeito às consoantes dependentes do contexto, a consoante substituta tem o valor fonético mais frequente da consoante original, tal como foi encontrado noutros estudos (BARCA et al., 2007; FOWLER et al., 1977; GOIKOETXEA, 2006; PINHEIRO, 1994, 1995; SALLES; PARENTE, 2007; VALLE-ARROYO, 1989). Esses dados devem-se, talvez, à grande variabilidade dos fonemas consonantais, especialmente no caso das consoantes fricativas [s, $\left.\mathrm{z}, \int, 3\right]$, que podem suscitar maior dificuldade, o que acontece pelo facto de esses fonemas apresentarem vários grafemas possíveis na escrita, necessitando haver uma aprendizagem consolidada das regras regulares contextuais de correspondências fonema-grafema (FREITAS et al., 2012). 0 mesmo acontece com a consoante $<\mathrm{x}>$ em contexto de palavras irregulares (PINHEIRO, 1995; PINHEIRO et al., 2008; SALLES, 2005).

Os erros de substituição da vogal ocorrem predominantemente na vogal $<0>$, lida como [u]. 0 grafema $<0>$ tem diversos valores fonéticos, o que poderá levar a essa confusão entre os fonemas [o] e [u], especialmente na fase inicial de aprendizagem da leitura.

Em relação ao grupo de dígrafos consonantais, ocorrem diversos erros, principalmente do tipo de substituição de um fonema por outro, tanto no $1^{\circ}$ ano como no $2^{\circ}$ ano. Os dígrafos $<\mathrm{ch}>$ e $<\mathrm{lh}>$ são frequentemente substituídos pelo dígrafo [n]. Essa substituição poderá ser eventualmente explicada devido ao dígrafo [n] ser o mais precocemente adquirido na linguagem oral (FREITAS et al., 2012).

Em relação ao grupo dos dígrafos vocálicos, as crianças do $1^{\circ}$ ano, para ultrapassarem a dificuldade de leitura desses dígrafos, suprimem a nasalização ou adicionam uma vogal à sílaba, transformando a sílaba em duas sílabas CV. No $2^{\circ}$ ano, esse mecanismo de adicionar uma vogal desaparece, o que parece evidenciar que é um processo mais básico, mas mantém-se a estratégia de supressão da nasal. Gomes (2001) também encontrou resultados semelhantes.

Outra subcategoria dos erros fonológicos diz respeito aos erros de adição que ocorrem de uma forma mais notória em sílabas complexas CCV, em que as crianças exibiram maior dificuldade. Essas sílabas são, frequentemente, transformadas em CVCV. Segundo Monteiro e Soares (2014), a conjugação de uma consoante com uma vogal seria o modelo de decodificação-base, ao qual as crianças voltariam quando enfrentam dificuldades com as sílabas complexas. Podemos também verificar que a adição nesse tipo de sílabas é sobretudo de vogais, nomeadamente o [e], tal como Gomes (2001) também refere.

No que diz respeito à subcategoria dos erros de supressão, estes se encontram no mesmo lugar na hierarquia de erros no $1^{\circ}$ e no $2^{\circ}$ ano. A supressão acontece maioritariamente com as consoantes e as crianças fazem esse tipo de erro para resolverem situações variadas, sem um padrão bem definido. No entanto, podemos ver que a supressão surge, maioritariamente, como forma de resolução da leitura de sílabas complexas ou de sílabas contendo dígrafos. 
Em relação à subcategoria dos erros de acentuação, estes são frequentes ao longo dos dois anos de escolaridade e ocorrem maioritariamente por omissão da acentuação marcada na palavra.

Os erros de inversão são os menos frequentes. Porém, quando ocorrem, é geralmente para transformar sílabas CCV em sílabas CVC, isto é, para simplificar a estrutura silábica da palavra. A complexidade silábica influencia o desempenho na leitura, tal como foi realçado por Goikoetxea (2006) e Gomes (2001).

No início da alfabetização, as crianças, ao adquirirem o princípio alfabético, geralmente aprendem a leitura de sílabas com estrutura canónica e fazem inicialmente uma leitura silábica. 0 mecanismo de combinação das letras é realizado no contexto de sílaba canónica ou padrão CV (MONTEIRO, 2007).

Em conclusão, as dificuldades iniciais que as crianças apresentam na leitura poderão ser atribuídas a questões de recodificação fonológica, desconhecimento de regras de correspondência grafema-fonema, bem como ao conhecimento pouco interiorizado de certas estruturas silábicas complexas da ortografia portuguesa.

Quanto às implicações educativas deste estudo, diremos, por um lado, que o conhecimento do padrão evolutivo dos erros de leitores principiantes na leitura oral de palavras pode permitir uma melhor avaliação do processo de aprendizagem da leitura; diremos, por outro lado, que o conhecimento das correspondências grafema-fonema e das estruturas silábicas em que mais frequentemente esses erros ocorrem poderá permitir o delineamento de estratégias de ensino especificamente direcionadas para essas dificuldades; diremos, finalmente, que uma melhor compreensão dos processos usados pelas crianças na resolução dos problemas que as características da língua portuguesa lhes colocam poderá permitir uma intervenção educativa que conduza a um maior sucesso na aprendizagem da leitura.

\section{Referências}

ALVES MARTINS, Margarida; SIMÕES, Edlia. Teste de reconhecimento de palavras para os dois primeiros anos de escolaridade. In: CONFERÊNCIA INTERNACIONAL DE AVALIAÇÃO PSICOLÓGICA: FORMAS E CONTEXTOS, 13., 2008, Braga. Actas da... Braga: Psiquilibrios, 2008.

ÁVILA, Clara Regina Brandão et al. Tipologia de erros de leitura de escolares brasileiros considerados bons leitores. Pró-Fono, Barueri, v. 21, p. 320-325, out./dez. 2009.

BARCA, Laura et al. Context-sensitive rules and word naming in Italian children. Reading and Writing: An Interdisciplinary Journal, v. 20, p. 495-509, 2007.

COLTHEART, Max. Modeling reading: the dual-route approach. In: SNOWLING, Margaret J.; HULME, Charles (Ed.). The science of reading: a handbook. Oxford: Blackwell, 2005. p. 6-23.

COLTHEART, Max. Dual-route theories of reading aloud. In: ADELMAN, John (Ed.). Visual word recognition: models and methods, orthography and phonology. UK: Psychology Press, 2012. p. 3-27. 
COLTHEART, Max et al. DRC: a dual route cascaded model of visual word recognition and reading aloud. Psychological Review, v. 108, n. 1, p. 204-256, 2001.

COSSU, Giusseppe et al. Visual and phonological determinants of misreading in a transparent orthography. Reading and Writing: An Interdisciplinary Journal, v. 7, p. 235-256, 1995.

CUNHA, Vera Lúcia; CAPELLINI, Simone Aparecida. Caracterização dos tipos de erros na leitura de escolares de $1^{\mathrm{a}} \mathrm{a} 4^{\mathrm{a}}$ séries do ensino fundamental. Temas sobre Desenvolvimento, São Paulo, v. 17, n. 98, p. 74-8, 2010.

DEFIOR, Susana et al. Differences in reading acquisition development in two shallow orthografies: Portuguese and Spanish. Applied Psycholinguistics, Cambridge, n. 23, p. 135-148, 2002.

EHRI, Linnea. Development of sight word reading: phases and findings. In: SNOWLING, Margaret J.; HULME, Charles (Ed.). The science of reading: a handbook. Malden: Blackwell, 2005. p. 135-154.

EHRI, Linnea; SOFFER, Alison G. Graphophonemic awareness: development in elementary students. Scientific Studies of Reading, v. 3, n. 1, p. 1-30, 1999.

FERNANDES, Sandra et al. Reading and spelling acquisition in European Portuguese: a preliminary study. Reading and Writing, v. 21, p. 805-821, 2008.

FOWLER, Carol et al. On interpreting the error pattern in beginning reading. Language and Speech, n. 20, p. 162-173, 1977.

FREITAS, Maria João et al. Os sons que estão dentro das palavras: descrição e implicações para 0 ensino do português como língua materna. Lisboa: Colibri: Associação de Professores de Português, 2012.

GOIKOETXEA, Edurne. Reading errors in first and second-grade readers of a shallow orthography: evidence from Spanish. British Journal of Educational Psychology, n. 76, p. 333-350, 2006.

GOMES, Inês. Ler e escrever em português europeu. 2001. Tese (Doutorado em Psicologia) Universidade do Porto, Porto. 2001.

GOULANDRIS, Nata. Avaliação das habilidades de leitura e ortografia. Tradução de Magda França Lopes. In: SNOWLING, Margaret; STACKHOUSE, Jack (Ed.). Dislexia, fala e linguagem: um manual do profissional. Porto Alegre: Artmed, 2004. p. 91-120.

JIMÉNEZ, Juan; HERNÁNDEZ, Isabel. Word identification and reading disorders in the Spanish language. Journal of Learning Disabilities, v. 33, n. 1, p. 44-60, 2000.

LOFF, Ariana; VALE, Ana Paula. Análise do padrão de erros de leitura de palavras em língua portuguesa nos quatro anos do $1^{\circ}$ ciclo do ensino básico. Revista Galego-Portuguesa de Psicología e Educación, $n$. extraordinário, p. 1047-1059, 2007.

LÚCIO, Patrícia Silva; PINHEIRO, Ângela Maria Vieira. Vinte anos de estudo sobre o reconhecimento de palavras em crianças falantes do português: uma revisão de literatura. Psicologia, Porto Alegre, v. 24, n. 1, p. 170-179, 2011. 
MCGEOWN, Sara et al. Individual differences in children's reading and spelling strategies and the skills supporting strategy use. Learning and Individual Differences, n. 28, p. 75-81, 2013.

MONTEIRO, Sara Mourão. 0 processo de aquisição da leitura no contexto escolar por alfabetizandos considerados portadores de dificuldades de aprendizagem. 2007. Tese (Doutorado em Educação) Universidade Federal de Minas Gerais, Belo Horizonte, 2007.

MONTEIRO, Sara Mourão; SOARES, Magda. Processos cognitivos na leitura inicial: relação entre estratégias de reconhecimento de palavras e alfabetização. Educação e Pesquisa, São Paulo, v. 40, n. 2, p. 449-465, 2014.

NUNES, Terezinha; ALDINIS, Athanasios. A closer look at the spelling of children with reading problems. In: NUNES, Teresinha (Ed.). Learning to read: an integrated view from research and pratice. Dordrecht: Kluwer, 1999. p. 155-171.

NUNES, Terezinha; BRYANT, Peter. Leitura e ortografia: além dos primeiros passos. Porto Alegre: Penso, 2014.

PINHEIRO, Ângela Maria V. Leitura e escrita: uma abordagem cognitiva. Campinas: Psy II, 1994.

PINHEIRO, Ângela Maria V. Reading and spelling development in Brazilian Portuguese. Reading and Writing: An Interdisciplinary Journal, v. 7, n. 1, p. 111-138, 1995.

PINHEIRO, Ângela Maria et al. Tarefa de leitura de palavras em voz alta: uma proposta de análise dos erros. Revista Portuguesa de Educação, Braga, v. 21, n. 2, p. 115-138, 2008.

RAHBARI, Noriyeh; SÉNÉCHAL, Monique. Learning to read and spell in Persian: A cross-sectional study from grades 1 to 4. Developmental Psychology, v. 46, n. 6, p. 1514-1527, 2010.

REGO, Lúcia Lins; BUARQUE, Lair Levi. Algumas fontes de dificuldade na aprendizagem de regras ortográficas. In: MORAIS, Artur G. (Ed). 0 aprendizado da ortografia. Belo Horizonte: Autêntica, 1999.

SALLES, Jerusa. Habilidades e dificuldades de leitura e escrita em crianças de $2^{\mathrm{a}}$ série: abordagem neuropsicológica cognitiva. 2005. Tese (Doutorado em Psicologia) - Universidade Federal do Rio Grande do Sul, Porto Alegre, 2005.

SALLES, Jerusa; PARENTE, Maria Alice M. Pimenta. Avaliação da leitura e escrita de palavras em crianças de $2^{a}$ série: abordagem neuropsicológica cognitiva. Psicologia, Porto Alegre, v. 20, n. 2, p. 220-228, 2007.

SERRANO, Fernando et al. Variations in reading and spelling acquisition in Portuguese, French and Spanish: a cross-linguistic comparison. Journal of Portuguese Linguistics, v. 9, n. 10, p. 183-204, 2010.

SEYMOUR, Phillipe et al. Foundation literacy acquisition in European orthographies. British Journal of Psychology, v. 94, n. 2, p. 143-174, 2003. 
SPRENGER-CHAROLLES, Liliane; Siegel, Linda. A longitudinal study of the effects of syllabic structure on the development of reading and spelling skills in French. Applied Psycholinguistic, v. 18, n. 4, p. 485-505, 1997.

VALLE-ARROYO, Fernando. Reading errors in Spanish. In: AARON, P. G.; JOSHI; R. Malatesha (Ed.). Reading and writing disorders in different orthographic systems. Dordrecht: Kluwer Academic Publishers, 1989. p. 163-175.

Recebido em: 28.06.2016 Aprovado em: 04.04.2017

Edlia Simões é doutorada em psicologia educacional pelo Instituto Universitário de Ciências Psicológicas, Sociais e da Vida (ISPA), Lisboa, Portugal. Foi bolseira de doutoramento da Fundação para a Ciência e a Tecnologia (FCT). Atualmente leciona na Universidade de Saint Joseph e é colaboradora do Centro de Investigação em Educação (CIE-ISPA).

Margarida Alves Martins é professora catedrática de psicologia da educação no Instituto Universitário de Ciências Psicológicas, Sociais e da Vida (ISPA), Lisboa, Portugal, dirige o Centro de Investigação em Educação (CIE-ISPA), onde desenvolve investigação sobre os processos de aprendizagem da escrita e da leitura. 